Instructions for authors, subscriptions and further details:

http://brac.hipatiapress.com

\title{
El Aliento Invisible: Música y Sonido en la Obra de Gaudí.
}

Josep Gustems-Carnicer ${ }^{1}$, Diego Calderón-Garrido², Eugènia ArúsLeita $^{3}$

1) Facultad de Educación, Universitat de Barcelona. España

2) Facultad de Educación, Universidad Internacional de La Rioja. España.

3) Facultad de Educación, Universitat de Barcelona. España

Date of publication: February $3^{\text {rd }}, 2018$

Edition period: February 2018 - June 2018

To cite this article: Gustems-Carnicer, J., Calderón-Garrido, D. y ArúsLeita, E. (2018). El Aliento Invisible: Música y Sonido en la Obra de Gaudí. Barcelona, Research, Art, Creation, 6(1) 72-89. doi: 10.17583/brac.2018.2385

To link this article: http://dx.doi.org/10.17583/brac.2018.2385

\section{PLEASE SCROLL DOWN FOR ARTICLE}

The terms and conditions of use are related to the Open Journal System and to Creative Commons Attribution License (CC-BY). 
BRAC - Barcelona Research Art Creation. Vol. 6 No. 1, February 2018, pp. 72-89

\section{The Invisible Breath: Music and Sound in the Work of Gaudí}

Josep Gustems-Carnicer, Diego Calderón-Garrido, Eugènia Arús-Leita.

Universitat de Barcelona. Universidad Internacional de La Rioja, Universidat de Barcelona (Spain)

(Received: 11 October 2017; Accepted: 14 October 2017; Published: 3 February 2018)

\section{Abstract}

The figure of Antonio Gaudí has been analysed in many occasions, because he is one of the most influential architects in the world. In this paper we leave aside the most central elements of his work to delve into the aspects of sound, much that are more unnoticed. To do this, we firstly describe the different sound environments in which the artist grew up, matured and professionally developed and accompanied his daily life, especially the influence of traditional Catalan music and Gregorian chant. After that, the main sound elements are analyzed in three of their most emblematic creations: Park Güell, La Pedrera and Sagrada Familia. In this way, we described how, through acoustics zones created with different architectural elements, the dichotomy of sound spaces, free rhythm, intentional use of reverberation, bell design, organ placement and Spaces reserved for the corals, Gaudí gave to its creations a spiritual depth that transcended of the visual aspects to enter in the magic of the sound.

Keywords: Gaudi, music, sound, architecture 
BRAC - Barcelona Research Art Creation. Vol. 6 No. 1, February 2018, pp. 72-89

\section{El Aliento Invisible: Música y Sonido en la Obra de Gaudí}

Josep Gustems-Carnicer, Diego Calderón-Garrido, Eugènia Arús-Leita. Universitat de Barcelona, Universidad Internacional de La Rioja, Universitat de Barcelona (España)

(Recibido: 11 octubre 2017; Aceptado: 14 octubre 2017; Publicado: 3 febrero 2018)

\section{Resumen}

La figura de Antonio Gaudí ha sido analizada en múltiples ocasiones, pues se trata de uno de los arquitectos más influyentes de todo el mundo. En este artículo se dejan de lado los elementos más centrales de su obra para adentrarnos en los aspectos auditivos, mucho más desapercibidos. Para ello, en primer lugar, se describen los diferentes ambientes sonoros en los que el artista creció, maduró y se desarrolló profesionalmente y que acompañaron su día a día, en especial la influencia de la música tradicional catalana y el canto gregoriano. Posteriormente se analizan los principales elementos sonoros en tres de sus creaciones más emblemáticas: el Park Güell, la Pedrera y la Sagrada Familia. De esta forma se constata cómo a través de las zonificaciones acústicas creadas con los diferentes elementos arquitectónicos, la dicotomía de los espacios sonoros, el ritmo libre, el uso intencional de la reverberación, el diseño de las campanas, la colocación de los órganos y los espacios reservados para las corales, Gaudí otorgó a sus creaciones una profundidad espiritual que trascendía de los aspectos visuales para adentrarse en la magia del sonido.

Palabras clave: art processual, imaginari contemporani, reclusió, excavació, forat 
$\mathrm{H}$

ensbergen encabeza su magnífica monografía sobre Gaudí con la cita de G. B. Shaw: "el hombre razonable se adapta al mundo; el hombre poco razonable insiste en tratar de adaptar el mundo a sí. Todo progreso depende por tanto del hombre poco razonable" (2001, p. 11). No es nuestro objetivo juzgar la razonabilidad del arquitecto, pero sí reconocer su importancia en el progreso del mundo -en general y de Barcelona- en particular, y señalar qué papel desempeñaron la música y el sonido en todo este proceso y en una nueva forma de entender la arquitectura. El reclamo de Gaudí representa un altísimo porcentaje del PIB de la ciudad condal, que recibe más de 8 millones de turistas cada año que se pasean por sus edificios (Ajuntament de Barcelona, 2016); unas obras que escapan de los cánones tradicionales para crear un lenguaje esculpido en la piedra (Bergós y Llimargas, 1999) y que "habla tanto al alma de los más humildes como de los más cultos”, cualidad que Fulcanelli atribuía a las catedrales (1971, p. 48).

Un artista y una obra que no han dejado indiferente a ningún colectivo, estando de moda tanto en los círculos anarquistas como en los católicos (Hensbergen, 2001), cruzando el atlántico para exhibirse en 1957 en el MoMA de Nueva York, incitando a los académicos de la Universidad de Barcelona a la creación de una Cátedra Gaudí en 2015 respaldada por un Congreso Internacional bianual desde 2014, e incluso proponiendo su beatificación en junio del 2016. No en vano, estamos ante un genio, que cuenta con siete obras inscritas en la Lista del Patrimonio Mundial de la UNESCO.

La fama internacional de su obra contrasta con una visión del mundo de carácter catalanocentrista (solo viajó una vez al sur de Francia y como l'Emigrant de Amadeu Vives, afirmó que nunca más saldría de Catalunya), con un marcado fondo trágico (Carandell, 2006), y un ideario definido magistralmente por Hensbergen (2001) como una conjunción de catolicismo, romanticismo, fraternidad, amor por las causas perdidas y por las ruinas.

Su religiosidad le llevó a vivir con la austeridad de un monje más que un fraile (Bergós y Llimargas, 1999), pretendiendo situar a Catalunya en el centro mismo de la cristiandad (Milá, 1994) a lo cual dedicó gran parte de su obra ${ }^{1}$. Una personalidad marcada por la añoranza de un mítico pasado medieval ${ }^{2}$, siendo un profundo admirador del gótico catalán, a modo de leitmotiv en sus creaciones. Su amor por la naturaleza le acercó al excursionismo influido por el Karelanismo finlandés, comprometido con buscar siempre el aire puro, el agua y una dieta vegetariana llevada a rajatabla, siguiendo las pautas del Dr. Kneipp, sacerdote alemán y médico naturista. 
Una personalidad, por otro lado, marcada por la soledad, la tenacidad, la obsesión y la exigencia (Hensbergen, 2001). Una personalidad, ante todo, que emanaba tal creatividad que sentía aburrimiento si usaba dos veces una misma solución, y que contagiaba a quienes trabajaban a su lado. Esta búsqueda de respuestas diversas lo llevaba a conjugar aparentes rarezas estructurales con funciones convencionales de sus edificios (Carandell, 2006). Pero también tenía sus debilidades, tales como la ambición, la falta de modestia, una tozuda obsesión por la perfección, la competitividad, el despotismo y la intolerancia (Hensbergen, 2001); en palabras de Carandell: "un hombre bajito, cargado de discursos. Con complejo de inferioridad y cargado de protagonismo" (2006, p. 45). Un pelirrojo al que "gastaban bromas y le hacían daño por la calle al ver en ellos -los pelirrojos- la imagen del diablo" (Carandell, 2006, p. 36) tal como era costumbre de la época.

Si bien en este artículo nos centraremos en la influencia que la música y el sonido tuvieron sobre la obra de Gaudí, no podemos olvidar cómo el arquitecto ha servido también de inspiración a músicos posteriores. Álbumes como "Gaudí" (Alan Parsons Project, 1987), "Gaudí, el musical de Barcelona" con música de Albert Guinovart y libreto de Jordi Galcerán y Esteve Miralles (2002), la ópera “Gaudí” compuesta por Joan Guinjoan con letra de J. M. Carandell y estrenada en el año 2004, el musical de Eric Woolfson "Gaudi” (1992), o la sardana "Parc Güell” compuesta por Francesc Mas en 1957, dan cuenta de ello.

La relación entre música y arquitectura siempre ha sido estrecha (Carles y Palmese, 2005), desde los paralelismos y metáforas (como la de Lord Byron al calificar la arquitectura como de "música congelada" en The Bride of Abydos, 1813; o la de Bosseur explicando que una de las principales propiedades del sonido es la de esculpir el espacio, 1998), mediante códigos simbólicos secretos en los capiteles de los claustros de algunos monasterios (Schneider, 2001), escultura e iconografía musical convencional, las esculturas sonoras - como los instrumentos Baschet (Ruiz y Ruiz, 2013)- o los algoritmos de la música estocástica, del arquitecto-compositor Iannis Xenakis (2009), entre otros.

Si bien esta relación es incuestionable, en el caso de Gaudí resulta especialmente llamativa, pues las alusiones tanto explícitas como implícitas a nuestro modo de ver, las más interesantes y que se examinarán en este artículo- que el arquitecto hizo al sonido fueron notables. En cualquier caso, y como resulta lógico, no estamos insinuando que otorgase supremacía a la música o al sonido en sus obras ${ }^{3}$, pero sí creemos poder afirmar que en sus creaciones la cartografía sonora, tal como la entiende Cerdà (2016), a modo 
de instalación sonora in situ (Straebel, 2008) tomaría especial relevancia. No en vano, para Gaudí, "el oído es el sentido de la fe" (Hensbergen, 2001, p. 296).

\section{La Música que Envolvió a un Genio}

Las diferentes etapas vitales del arquitecto están ligadas a los diversos contextos donde vivió y que fueron conformando su propia banda sonora. Así pues, sus inicios estuvieron marcados por el bronce, el cobre y el martilleo constante, característicos de la profesión de caldereros que ejercía su familia, una saga de artesanos que inculcó a Gaudí el amor y el compromiso por el trabajo y la búsqueda de la recompensa personal en dicho trabajo (Sennet, 2009). Sus primeros años discurrieron entre el sonido constante del viento, las tempestades y las hojas de los árboles en el Baix Camp tarraconense, un paisaje sonoro rural que se completaba con el ruido del chocar de las avellanas, del tren, de los perros y otros animales de granja (Hensbergen, 2001). Junto a esta idílica estampa campestre el pequeño Antoni aprendió los bailes, números y letras con los sonsonetes propios de la escuela privada Berenguer, en Reus, donde se inició en los estudios (Carandell, 2006).

En su adolescencia se le podía definir como un joven amante de la naturaleza, miembro de la Societat Catalana d'Excursions Cientifiques, donde tuvo la oportunidad de conocer a muchos intelectuales de su época. Desplazado a Barcelona para ingresar en la universidad, frecuentaba el café Pelayo, donde su vida se cruzó con Millet, Llongueres, o Albéniz. Frecuentaba el ambiente burgués del Liceu, a pesar de preferir a los catalanistas conservadores del Palau, y la música tradicional que allí se interpretaba: le apasionaba la música de Clavé, el compositor redentor de los obreros a través del arte (Carbonell, 2003). Un joven, en definitiva, admirador de Wagner que se codeaba con las clases altas de una Barcelona esnob conquistada por el exotismo oriental, junto con ciertas dosis de espiritismo y de sexualidad reprimida (Quintana, 2000). Fue en esta época cuando conoció a Eusebio Güell, mecenas de músicos como García Robles o Rodríguez de Alcántara. Fue entonces cuando se forjó su personalidad arrogante y extravagante, con su característico mal genio que le acompañaría toda su vida (Bergós y Llimargas, 1999).

Al llegar a la madurez, su vida experimentó un cambio radical, inclinándose a la austeridad y la sencillez, convirtiéndose en un cristiano practicante y en un artista comprometido con el significado trascendente de su obra. Siguiendo el rumbo marcado por sus creencias se retiró al Monasterio de Poblet junto a los monjes cistercienses, entre el repicar de campanas y los cantos gregorianos que, aún hoy en día, acompañan todas las liturgias diarias. 
Es en esta época cuando, sin duda, se enamoró de la aparente simplicidad del canto colectivo que ya había conocido anteriormente gracias a Clavé y que le llevó a afirmar que "en el cielo todos seremos orfeonistas" (ver figura 1). Allí en Poblet, junto a Baixeras, Verdaguer y Brel, creó en 1882 un espectáculo con bengalas de colores y sonido a modo de son et lumière, provocando una luz fosforescente, evocadora en la vaporosa niebla que envolvía las ruinas del monasterio. Espontáneamente, los asistentes comenzaron a cantar la Salve Regina devotamente emocionados (Hensbergen, 2001). Inmersos en un proceso de modernización los sectores dirigentes de la Iglesia Catalana se propusieron sofisticar y depurar su liturgia, preocupándose por su dimensión cultural y estética y en contrapartida jugando un papel fundamental en materias de arte y estética. Gaudí, Maragall, Llimona, Millet... se adherirán a este proceso dando todo su apoyo a la iglesia (Artís y Millet, 1991).

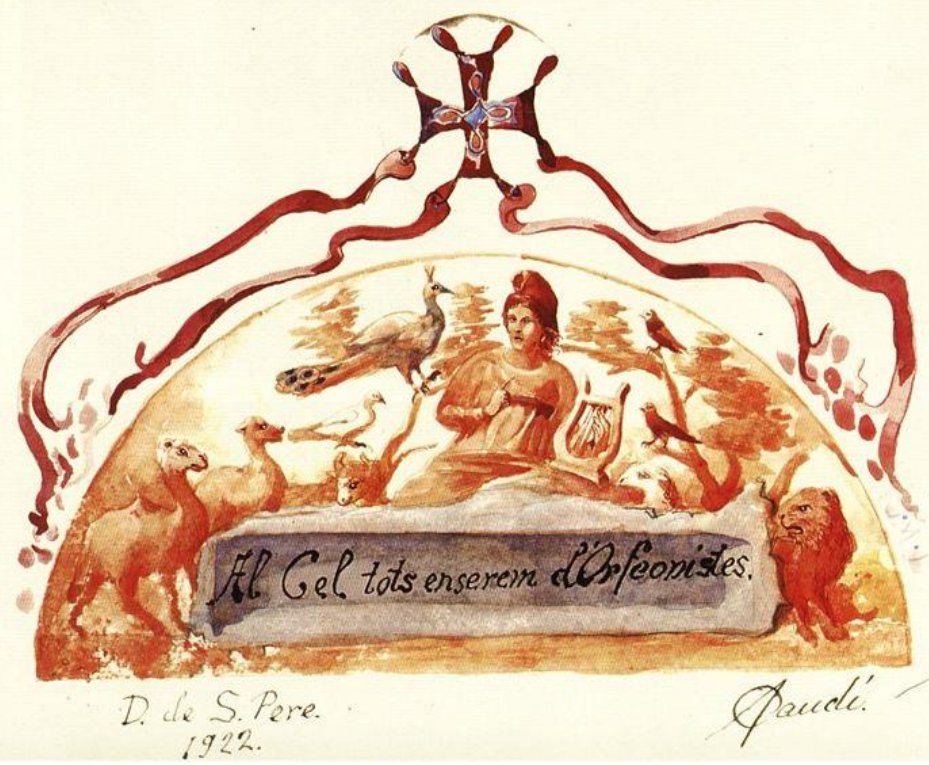

Figura 1. Dedicatoria del Orfeó Català, de Antoni Gaudí, 1922.

En su etapa más conocida, la que corresponde a la segunda madurez y la vejez, podríamos calificar a Gaudí como de "sacerdote artista". Fue también su etapa más productiva, en la que quería dotar a sus edificios de una dimensión moral y construir la "Nueva Jerusalén", a imitación de arquitectos como Juan Bautista Villalpando. Esa pretensión le llevó a utilizar el simbolismo, la mitología, el detalle elocuente -que desvela con lentitud-, o la 
metáfora arquitectónica, persiguiendo un nuevo orden social. Una etapa marcada por la penitencia y en la que la construcción del Templo Expiatorio de la Sagrada Familia fue, según él, la gran alternativa espiritual para que esta ciudad purgara sus contradicciones y desigualdades sociales, su perversidad y corrupción. Una etapa, en definitiva, marcada por la oración, la soledad, la caridad, la humildad, el ascetismo y el ayuno (Hensbergen, 2001), que acercan al individuo a la visión de Dios como fin último, tal como propusiera la Imitación de Cristo, su libro de cabecera (Kempis, 1999).

Fueron años marcados por la rutina de sus paseos, sus oraciones matinales y su misa diaria en S. Felip Neri, donde coincidía con Millet. Una rutina que duró hasta 8 meses antes de su muerte, cuando se trasladó a vivir en el mismo Templo. Una rutina que le llevaba a pie desde su residencia en el Park Güell a la Sagrada Familia, después a S. Felip Neri y volvía de nuevo a casa caminando (Guix, 1960). Un periodo en el que los sonidos de un paisaje urbano semi-residencial, el canto gregoriano y el órgano, y sus amigos músicos siguieron a su lado, conociendo a grandes artistas como Albert Schweitzer en su interpretación de la Pasión según San Mateo de J. S. Bach (1921) con el Orfeó Catalá, bajo la batuta de su amigo Lluís Millet.

Su muerte, al igual que su vida, estuvo acompañada por la música. En este caso fue el Orfeó Català con su interpretación del estremecedor responsorio Libera Me de Tomás Luís de Victoria, que acompañó el descenso de su cuerpo a la cripta de la Sagrada Familia, en 1926, donde permanece enterrado. Desde ese día, la campana que el genio creó y que situó en la única torre acabada por aquel entonces, la de San Bernabé, ha permanecido muda (Santana, 2009).

\section{El Sonido y la Música en la Obra de Gaudí}

Después de todo lo descrito, vamos a analizar algunos elementos sonoros que nos permitirán dar mayor sentido a su obra. En algunos casos, dichos elementos son visibles y, en otros, se esconden a la vista del gran público, pero en todos ellos la naturaleza y la recreación de ésta funciona como protagonista. No podemos olvidar el sentimiento y la fuente de inspiración que el arquitecto encontró en la naturaleza (Carandell, 2006) y su intento de retornar a los orígenes, donde "el creador" actuó.

En cualquier caso, Gaudí realizó destacadas zonificaciones acústicas en sus edificios, creando elementos de gran importancia para el aislamiento sonoro entre sus espacios. Para ello se basaba en la flexibilidad y el comportamiento de algunos materiales, en las fachadas internas amortiguadoras de sonido, o la separación de espacios por sonidos, materiales y formas. Todo ello revestido con fachadas externas que perseguían crear un 
espíritu misterioso y místico, intentando aislar a los edificios del exterior mundano. De esta forma creó una vida sonora propia, que buscaba hacer de su obra arquitectónica una sinfonía en sí misma, compuesta de formas, espacios y sonidos (Daumal y Campos, 2015).

Para explicar el papel que jugó la música y el sonido en la obra de Gaudí, vamos a repasar algunas de las características de algunos de sus edificios y construcciones más emblemáticas de Barcelona; en concreto, el Park Güell, la Pedrera y la Sagrada Familia, fijándonos especialmente en tres elementos sonoros principales: la reverberación o su ausencia -el aislamiento acústico-, el canto gregoriano y las campanas.

Así, por ejemplo, en el caso del Park Güell, cada uno de los diferentes pisos de piedra, cemento o arena provoca su propio sonido característico. De esta forma, podemos escuchar una extraordinaria gama de éstos en los espacios en los que el agua es la protagonista, mezclándose con los elementos naturales que invitan al recogimiento espiritual y abstracción de los murmullos sonoros del ambiente (Daumal y Campos, 2015), o la particularidad del sonido de los pasillos de arena producido por los pasos propios al mezclarse con los ajenos, etc. Todo esto se debe al contraste de los materiales usados, acordes a las características acústicas de la zonificación, básicamente con dos ideas opuestas.

Por un lado, en las áreas de recepción donde se aglomera el gran público, utilizó difusores de sonido que, junto con las formas cóncavas y las grandes alturas generan espacios reverberantes de gran sonoridad, utilizando materiales que incrementan el sonido, como los fragmentos de botellas de vidrio, el cemento y los azulejos troceados. Por otro lado, para crear espacios silenciosos como por ejemplo bajo los viaductos, empleó grandes piedras porosas, sumamente rústicas y absorbentes, así como arena. Para Campos (2002) los conocimientos acústicos de Gaudí influyeron en la elección y distribución intencionada de tales materiales.

El silencio puede ser considerado como un sonido interior, una música propia, sin límites, donde el ritmo, la sonoridad y la verdad se funden y se escuchan de forma clara y transparente. Esta idea invadió la pedagogía musical catalana de principios del siglo XX que buscaba formas para desarrollar la audición interior del estudiante partiendo del silencio y apoyándose en el movimiento. Este pensamiento actuará como fuente de inspiración para diferentes artistas como Frederic Mompou, músico de pocas palabras que compone la Música Callada, un sonido del silencio inspirado por los poemas de San Juan de la Cruz. Sus indicaciones de expresión invitan al intérprete a ralentizar los sonidos hasta el extremo, encontrando sonoridades 
y ritmos fuera del tiempo que lo transportan a un mundo verdaderamente interior. Llongueres nos habla incluso del ritmo de la paz del alma que percibimos al estar en silencio (Llongueres, 1935).

Esta construcción provoca, como hemos descrito, grandes dicotomías sonoras como la producida entre la falta de reverberación en el espacio abierto del teatro y el exceso de ésta en la gran sala hipóstila (ver figura 2), donde hay una resonancia larguísima de 4 segundos en frecuencias bajas (entre 125 y 250 $\mathrm{Hz}$ ), lo que provoca que una persona pueda hablar desde detrás de una columna sin ser vista y no poder ser localizada a través de la escucha, una suerte de "escondite sónico" (Daumal y Campos, 2015). El resultado sonoro obtenido en tales espacios es fruto de la acción de los visitantes junto a las características intencionadas de su creador, en línea con lo que Eco en 1962 desarrolló en su concepto de "opera aperta" (Eco, 1984), un espacio sonoro cambiante y significativo.

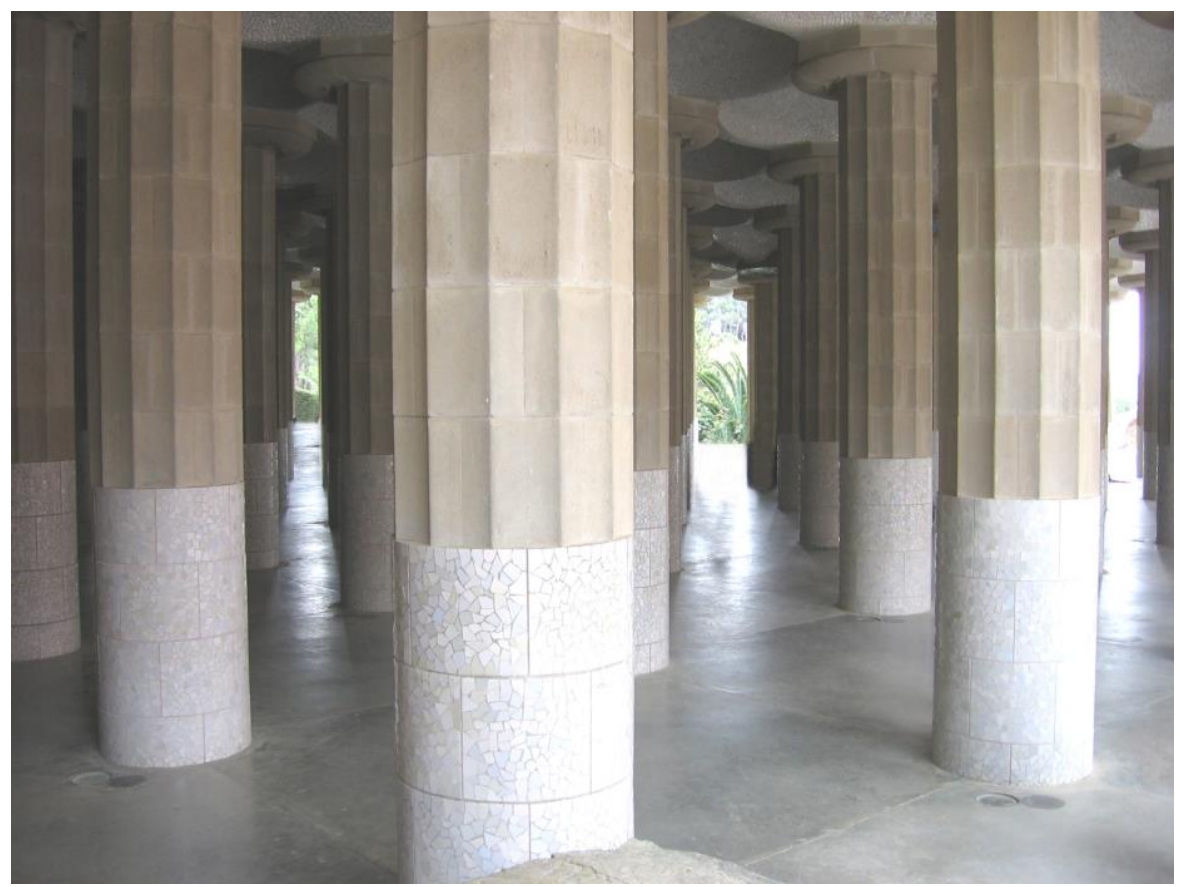

Figura 2. Sala hipóstila del Park Güell, de Antoni Gaudí, 1908-09. 
Si para Gaudí, "el gran libro siempre abierto es el de la naturaleza" (Carandell, 2006, p. 18), la posibilidad de comprender e interpretar sus leyes colaborando y continuando con la creación divina es algo que cada vez interesó más al artista. Sin entrar en consideraciones acústicas como las anteriores, esto lo encontramos perfectamente representado en La Pedrera, un edificio que muestra su estilo maduro donde la estructura, el tema, la función y la decoración resultarán perfectamente amalgamados (Hensbergen, 2001).

Gaudí planteó el edificio con una portada singular de formas onduladas caprichosas, inspiradas quizás en los fondos de arena de las playas cercanas (ver figura 3). El aparente movimiento de la fachada, equilibrio desordenado, se nos revela como una metáfora de estilos musicales inspirados en el ritmo libre, a modo de melismas melódicos. La música tradicional, tan admirada por el arquitecto, es un claro ejemplo del delicado equilibrio entre la simetría (regularidad) y su ruptura: en el ritmo encontraríamos la simetría, en la melodía y la armonía, la ruptura (Caglioti, 1992). El canto gregoriano, por su parte, planteaba una riqueza rítmica que en la actualidad se perdió con el contacto e hibridación con la polifonía clásica y los intentos de restauración mensural de la Abadía de Solesmes ${ }^{4}$, con el llamado cantus planus.

La variedad de matices (notas pesadas, ligeras, importantes, regularidades, aceleraciones, retardos, etc.) que se proponen en sus intentos de reconstrucción interpretativa (Sunyol, 1925), fascinaron al arquitecto, quien decidió, junto a su amigo Lluís Millet, asistir al curso de canto gregoriano impartido por el padre G. Sunyol en 1918, donde, según sus palabras "allí aprendía arquitectura, no música" (Carandell, 2006, p. 193).

Musicalmente, los artistas catalanes ahondaron en sus raíces y algunos se verían influenciados por una corriente mística que quería dotar a los sonidos de una fuerte espiritualidad. De esta influencia artística no escaparía la pedagogía musical de la época; así comenta Joan Llongueres en una visión retrospectiva de su educación por y para el ritmo: "Un retorno al ritmo significa un retorno a la meditación y a la vida interior, un retorno al conocimiento claro y justo de la Naturaleza. Un retorno al equilibrio y a la justeza y a la profundidad del conocimiento en sí, en su significación más alta y más sublime" (Llongueres, 1942, pp. 26-27). 


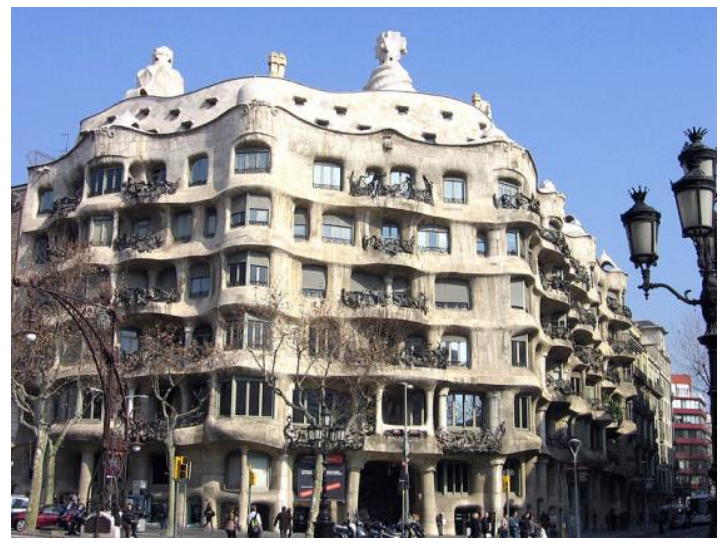

Figura 3. Fachada de la Casa Milá ("la Pedrera"), de Antoni Gaudí, 1906-10.

En esa búsqueda de lo propio y lo espiritual se estudia la pureza de la melodía y por ello se contempla el ritmo libre y natural. Se preguntaba Millet ¿Y dónde queda nuestra tradición artística? Encontraría la respuesta en un recorrido histórico donde música y arquitectura se entrelazaban, ejemplo de ello es la similitud que hace entre el motete de la polifonía clásica y la catedral gótica (Millet, 1917). Así pues, el canto gregoriano será apreciado, un sonido donde "el ritmo se libera de la simetría de la danza y la melodía se espiritualiza" según palabras del propio Millet (1917, p. 92). A esta búsqueda se añadirá el gusto por la polifonía que acerca al sonido a su expresión más mística y el reencuentro con la música popular como base para la renovación de formas musicales. La creación del Orfeo Català por el mismo Millet sería claro ejemplo de este empeño colectivo.

Pero sin duda es en su obra más emblemática, la Sagrada Familia, donde podemos observar más elementos que delatan al arquitecto en su interés por un tratamiento específico del sonido. Así pues, como sucede en todos los templos, el silencio reinante invita a la oración y a la meditación. Ya desde la Roma antigua la ausencia de sonido, la expresión favete linguis o parcete linguis, que se podría traducir por "guardar silencio", se pronunciaba antes de hacer un sacrificio o de realizar una plegaría, ya que ese silencio es el que pretendidamente reclamaban los dioses para actuar (Miró y Espluga, 2002). No en vano, en las criptas, el visitante experimenta una sensación singular que le impone guardar silencio (Fulcanelli, 1971). Gaudí buscó está sensación mediante un pavimento de corcho que, además de mejorar el aislamiento térmico, amortiguaba el sonido de los zapatos de los asistentes. 
Uno de los focos sonoros más espectaculares que Gaudí diseñó para la Sagrada Familia reside en los campanarios. Su pluralidad resulta llamativa, pues lo habitual en los templos es un único campanario (Santana, 2009). En vez de esto, el arquitecto forjó un concepto único e integrado del que formarían parte un mínimo de 84 campanas (Santana, 2016) ubicadas a lo largo de 12 campanarios (Álvaro y Llop, 2016). Este despliegue convertiría al conjunto arquitectónico en un inmenso carrillón, capaz de acompañar los cantos de las procesiones y proporcionar a la ciudad conciertos de música sacra en fechas señaladas (Bergós y Llimargas, 1999).

Cada uno de los campanarios estaba provisto, desde su diseño primigenio, de una serie de persianas orientadas hacia abajo con pequeñas oberturas a modo de tornavoces. De esta forma el repicar no se pierde en el aire como sucede en las catedrales góticas que estaban dedicadas a Dios, sino que el sonido va hacia abajo, hacia los barceloneses, los principales destinatarios de la Sagrada Familia (Carandell, 2006). Este aspecto es similar, aunque mucho más elaborado, al de los difusores de los campanarios de Nôtre Dame, en París (Daumal y Campos, 2015). Estas aberturas provocan un misterioso aulllido flautato los días de vendaval, que ya Joan Maragall en 1900 describió: la piedra que murmura trata de decir Noël (Blasco, 2002), un intrigante ulular navideño.

En cualquier caso, el elemento más innovador y singular de los campanarios fueron las campanas tubulares que debían albergar, de las cuales solo se conserva la de la torre de S. Bernabé (ver figura 4). No sabemos si dicha campana era un prototipo o un proyecto ya acabado, junto a la cual pasan los visitantes sin percatarse de su importancia. La campana no tiene ninguna marca de fábrica, ni señal de uso ni el tipo de mecanismo del cual pendía, ni el artilugio con el que podía ser tocada. Se trata de una campana construida en bronce de una elevada densidad $\left(8,9 \mathrm{~g} / \mathrm{cm}^{3}\right)$ cuya nota prominente es un La $(220 \mathrm{~Hz})$, con los sobretonos de Re, Si y Fa\#, conformando el sonido grave (Santana, 2009). Esto provoca que si la campana fuese golpeada sonaría la nota La, la cual se acabaría rápidamente, momento en el que se podrían empezar a distinguir unos armónicos bastante graves, casi estremecedores, que conformarían el acorde de Si menor (Sadie, 1980). No es la única muestra de sus singularidades en el diseño de las campanas. A la entrada de la cripta hay una campanilla sin ninguna inscripción, de unos $20 \mathrm{~cm}$. de diámetro, situada a una gran altura, desprovista de cualquier mecanismo para poder tocarla. Igualmente, en otro de los edificios del conjunto, hay una espadaña vacía. 


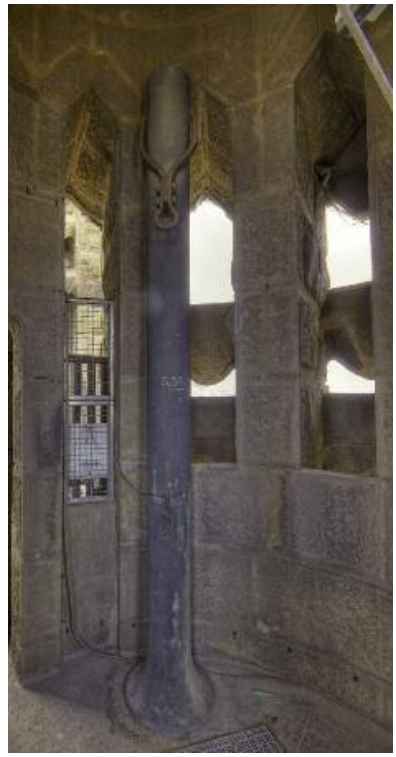

Figura 4. Campana en la torre de S. Bernabé.

La campana de la torre de s. Bernabé debía formar parte de un inmenso carrillón de campanas tubulares capaz de interpretar música desde el propio templo como si fuese un gran teclado de 7 octavas que, según las noticias del Diario de Barcelona del 7 de mayo de 1915 y La Vanguardia del 8 de mayo, se dice que fueron puestas a prueba en un primer ensayo público ese mismo año (Puig, 1929), aunque su destino posterior parece incierto. Hoy en día, hay instalado un carrillón electrónico programado para ejecutar ciertas melodías, cada hora entre las 9 y las 21 horas, expandiendo sus sonidos a través de grandes altavoces. Esto supone para los vecinos del barrio otra incomodidad más, añadida a la de multitud de turistas y vehículos que invaden sus inmediaciones (Lluch, 2004).

Además de las campanas, en la Sagrada Familia destaca la reverberación en la nave central, recurso utilizado desde el arte rupestre para propiciar estados perceptivos alterados, desconcertantes, simbolizando la ubicuidad divina, singularizando espacios significativos con un uso ritual vinculado a la magia, al arte o a la religión (Diaz-Andreu y García Benito, 2013). No en vano, las dos tortugas de la fachada del Nacimiento nos advierten con sus caparazones de la siguiente paradoja: Festina Lente, "imprime lentitud a la prisa". 
Dentro del templo, en la nave principal, la resonancia oscila entre 11 y 13 segundos en función de la temperatura ambiente, lo que hace imposible la interpretación de cualquier música sacra que no sea gregoriana, o como mucho, de la Contrarreforma. La melodía modal del gregoriano, interpretada en un espacio de tal reverberación provoca una "auto-armonía", producida por la misma melodía en su ejecución simultánea. Esto, obviamente, estaba premeditado por el arquitecto, ferviente apasionado del canto gregoriano desde su estancia en Poblet (Hensbergen, 2001).

Esta música, el gregoriano, fue una de las apuestas del Papa Pius X que, en su encíclica E Supremi (1903) y posteriores publicaciones musicales (Gradual, 1907; Antifonario, 1912) justificó el protagonismo de este canto colectivo monódico, no como una involución, sino como un retorno a los orígenes, una idea en plena consonancia con la filosofía de Gaudí y que engloba además un sentido de identidad, ilusión y esfuerzo colectivos de sus miembros (Carbonell, 2003). El gregoriano, en su aparente simplicidad, esconde una tremenda riqueza rítmica y melódica que ha fundamentado buena parte de la música tradicional catalana, como mostrarían los trabajos de las Missions de recerca, que se iniciarían en 1922 promovidas por la Obra del Cançoner Popular de Catalunya (Massot, 1993). Para Gaudí, la cercanía de este canto con lo popular otorgaba cierta elegancia a la pobreza y a las clases populares; no en vano, su templo sería bautizado por el pintor Joaquim Mir como La Catedral dels pobres, en su lienzo de 1897-98, un retrato perfecto de su humildad franciscana y su amor por las ruinas y las obras inacabadas.

Gaudí, ahondando en el espíritu comunitario que deseaba para el templo, tenía en mente la sonoridad de un coro de 1.300 mujeres ubicadas perimetralmente a una altura de 15 metros sobre el nivel de la planta principal. De esta forma, el sonido llegaría a los fieles rodeándoles desde arriba, a modo de canto celestial ${ }^{5}$. Además, el Templo está diseñado para que los asistentes estén en el centro, cantando, acompañados por los cuatro órganos que deberían ubicarse a 45 metros de altura entre las columnas que sostienen el cimborio principal, con parte de la trompetería orientada a la Fachada de la Pasión para que toda Barcelona pudiera escucharla. De esta forma, se establecerían tres niveles sonoros cargados de simbolismo místico, en los que los fieles ocuparían el más bajo, los coros el intermedio y el sonido de los órganos en el superior (Daumal y Campos, 2015).

La Sagrada Familia constituye pues, un magnífico ejemplo de lo que Comelles y Ortuño (2015) denominan como "espacio audible", es decir, un espacio organizado intencionadamente de forma que sus elementos prácticos 
permitan una escucha adecuada a su secreto fundamental: subyugar acústicamente dentro y fuera del recinto en que se inscribe (Costa, 2015).

\section{Epílogo}

Acercase a la persona de Gaudí no resulta fácil, estamos ante una persona profundamente espiritual y luchadora, pero a su vez discordante y contradictoria. De hecho, acercarse a Gaudí es descubrir un artista marcado por el tradicionalismo, la originalidad, el barroquismo indulgente y el tecnicismo revolucionario. Es acercarse a un arquitecto radical, al que se ha llegado a comparar con Julio Verne, que proporcionó un nuevo concepto constructivo, una utilización original del espacio y la luz, la decoración, el color $\mathrm{y}$, como hemos visto de forma efectiva, también del sonido.

Gaudí decía que el oído no es tan perfecto como la vista porque requiere del tiempo. Su larga vida -74 años- le permitió el ejercicio constante de la observación que le llevaría al saber, una larga experiencia que le aseguraría el poder, una voluntad y confianza que le permitieron atreverse con todo y, cuando el éxito hubo consagrado tantos años de trabajo, despreciando las vanidades del mundo, se aproximó a los humildes, para siempre callar... más allá de la música.

\section{Notas}

${ }^{1}$ La Casa Vicens (Barcelona, 1880) fue la última obra de Gaudí que no estuvo fuertemente ligada a la fe cristiana (Hensbergen, 2001).

${ }^{2}$ En este sentido, una de las mayores influencias de Gaudí fue el Dictionnaire de l'architecture française du XIe au XVIe siècle (1854-1868) del emblemático restaurador del gótico Eugène-Emmanuel Viollet-le-Duc (Milá, 1994).

${ }^{3}$ Refuerza esta idea la anécdota de que, ante la dificultad logística que suponía colocar un piano de cola en la primera planta del Palau Güell, Gaudí sentenció: "Isabel, créame, ¡toque el violín!” (Hensbergen, 2001, p. 161).

${ }^{4}$ Dom Mocquereau, uno de los principales investigadores de Solesmes, planteó en su Paléographie (1889) regularizar los neumas a partir de combinaciones de 2 o 3 puntos, dando cierta libertad rítmica al discurso, aunque simplificando forzosamente los cambios de ritmo.

5 Todo lo contrario de lo que sucede en la Ópera de Bayreuth, diseñada por Wagner, donde la música de la orquesta llega desde un foso escondido en la parte inferior del escenario, donde está alojada. 


\section{Agradecimientos}

Queremos agradecer las facilidades dadas en el acceso al fondo de documentación del Institut Joan Llongueras, de Barcelona. Además, este trabajo ha sido financiado parcialmente mediante una ayuda de la Agrupación en Investigación en Ciencias de la Educación, de la Universidad de Barcelona (A.R.C.E., convocatoria 2015).

\section{Referencias}

Ajuntament de Barcelona. (2016). Estadístiques de Turisme, 2015. Barcelona: Ajuntament de Barcelona.

Álvaro, M. C., \& Llop, F. (2016). Inventario de las campaneas de las Catedrales de España.Madrid: Minsterio de Educación, Cultura $\mathrm{y}$ Deporte.

Artís, P. \& Millet, Ll. (1991). Orfeó Català. Llibre del Centenari 1891-1991. Barcelona: Barcino.

Bergós, J. \& Llimargas, M. (1999). Gaudí. L’home i l'obra. Barcelona: Lunwerg.

Blasco, A. M. (2002). Els articles de Maragall i de Pijoan sobre la Sagrada Família. Quaderns, 63, 87-95.

Bosseur, J. Y. (1998). Musique et Arts Plastiques. París: Minerve.

Caglioti, G. (1992). Rôle de la symétrie et de la rupture des symétries dans la musique. In M, Lundi (Ed.), Quadrivium, musiques et sciences (pp. 195199). Paris: Éditions IPMC.

Campos, J.A. (2002). Las voces de Gaudi. Barcelona: Edicions UPC.

Carandell, J. Mª (2006). Gaudi herètic. Reus: Centre de Lectura.

Carbonell, J. (2003). Aportaciones al estudio de la sociabilidad coral en la

España contemporánea. Hispania, 63(214), 485-504.

Carles, J. L. \& Palmese, C. (2005). Música y Arquitectura. Scherzo: Revista de música, 193, 113-133.

Cerdà, J. (2016). Sound Cartography of The Alhambra. The Sound of Water as a Forming Element of the Place. BRAC-Barcelona Research Art Creation, 4(3), 219-247.

Comelles, E. \& Ortuño, F. (2015). El espacio audible. Una primera aproximación a mostrar sonido en el espacio. Eufonía, Didáctica de la Música, 65, 9-13.

Costa, J.M. (2015). El arte sonoro expuesto. Exposiciones de arte sonoro en España desde 1990 hasta el presente. Córdoba: Bandaaparte.

Daumal, F. \& Campos, J. A. (2015). Las tonalidades de Gaudí. In J. L. Carles \& A. Nuñez Pérez (Ed.s) Espacios sonoros y audiovisuales 2013: 
creación, representación y diseño (pp. 187-204). Madrid: Universidad Autónoma de Madrid.

Díaz-Andreu, M. \& García Benito, C. (2013). Sound and ritual in Levantine art: a preliminary study. In R, Jiménez Pasalodos, et al. (Eds.), Music and Ritual: Bridging Material and Living Cultures (pp. 227-256). Berlin, Ekho Verlag.

Eco, U. (1984). Obra abierta. Barcelona: Ariel.

Fulcanelli. (1971). El misterio de las catedrales. Barcelona: Plaza \& Janés.

Guix, J.M. (1960). Defensa de Gaudí. Reus: Monterols.

Hensbergen, G. van. (2001). Antoni Gaudí. Barcelona: Plaza \& Janés.

Kempis, T. de. (1999/1406). Imitación de Cristo. México: Porrua.

Llongueres, J. (1935). Del ritme en la música i en la vida. Barcelona: Institut de Cultura i Biblioteca Popular de la Dona.

Llongueres, J. (1942). El Ritmo en la educación y formación general de la infancia. Barcelona: Labor.

Lluch, P. M. (2004). El carrillo de la Sagrada Familia. Barcelona: Asociación Catalana contra la Contaminación Acústica.

Massot, J. (1993). Inventari de l'Arxiu de l'Obra del Cançoner Popular de Catalunya. Barcelona: L'Abadia de Montserrat.

Milá, E. (1994). Guía de la Barcelona Mágica. Barcelona: Martínez Roca.

Millet, Ll. (1917). Pel nostre ideal. Recull d'escrits de Lluís Millet. Barcelona: Joaquím Horta.

Miró, M. \& Espluga, X. (2002). Vida religiosa a l'antiga Roma. Barcelona: Editorial UOC.

Pius X. (1903). Encíclica E Supremi. C. del Vaticano: Libreria Editrice Vaticana.

Puig, I. (1929). Problemes acústics. El temple de la Sagrada Familia. Barcelona: Barcino.

Quintana, L. (2000). La paradoxa del majordom. Guia pràcica per reconèixer un esnob. Barcelona: Ed. 62.

Ruíz, M. \& Ruíz, R. (2013). Escultura Sonora Baschet: Universal Design, Pedagogía e Inclusión. BRAC-Barcelona Research Art Creation, 1(1), 62-99.

Sadie, S. (1980). The New Grove Dictionary of Music and Musicians. Vol 15. Londres: Mc Millan.

Santana, G. (2009). La campana de la torre de Sant Bernabé de la Sagrada Família. Temple, 6, 12-15. 
Santana, G. (2016). Les campanes del registre exterior de carilló del gran orgue dissenyat per Gaudí per al temple de la Sagrada Família (tesis doctoral). Barcelona: UPC.

Schneider, M. (2001). El origen musical de los animales-símbolo. Madrid: Siruela.

Sennet, R. (2009). El artesano. Barcelona: Anagrama.

Straebel, V. (2008). Zur frühen Geschichte und Typologie der Klangstallation, In U. Tadday (Ed.) Musik Konzepte Sonderband Klangkunst (pp. 24-46). Bonn: Bild-Kunst.

Sunyol, G.M. (1925). Introducció a la Paleografia Musical Gregoriana. Barcelona: Abadia de Montserrat.

Xenakis, I. (2009). Música de la Arquitectura. Madrid: AKAL.

Josep Gustems-Carnicer: Profesor Titular de la Facultat d'Educació. Universitat de Barcelona.

\section{Email address: jgustems@ub.edu}

Contact Address: Facultat d'Educació, Universitat de Barcelona, Pg. Vall d'Hebron 171, Ed. Llevant 3a planta, 08035 Barcelona.

Diego Calderón-Garrido: Profesor de la Facultad de Educación de la Universidad Internacional de La Rioja, área de Didáctica de la Música.

\section{Email address: diego.calderon@unir.net}

Contact Address: Facultad de Educación, Universidad Internacional de La Rioja. Av. de la Paz, 137, 26006 Logroño, La Rioja.

Eugènia Arús-Leita: Profesora de la Facultat d'Educació, secció d'Educació Musical, Universitat de Barcelona

\section{Email address: mearus@ub.edu}

Contact Address: Facultat d'Educació, secció d'Educació Musical, Universitat de Barcelona. Passeig de la Vall d'Hebron 171, 08035 Barcelona 